\title{
Effects of Knife-incising and Longitudinal Kerfing Pretreatments on High-temperature Drying of Red Pine and Pitch Pine Timbers
}

\author{
Chang Jin Lee ${ }^{\mathrm{a}}$ and Chang-Deuk Eom ${ }^{\mathrm{b}, *}$ \\ Effects of knife-incising and longitudinal kerfing pretreatments were \\ analyzed relative to the high-temperature drying of red pine and pitch pine \\ timbers with cross-sections less than $15 \mathrm{~cm}$. Specimens were prepared as \\ round and square timbers with thicknesses of 9,12 , and $15 \mathrm{~cm}$. They were \\ divided into four groups: control, longitudinal kerf, knife-incised, and a \\ combination of knife-incised and longitudinal kerf. Some results from this \\ study, such as commercial availability and application methods of drying \\ schedules, have immense commercial importance. The incising and \\ kerfing treatment can be used not only to improve drying quality but also \\ as a tool for deriving an optimal drying schedule. The kerfing treatment \\ noticeably reduced the surface checks in square timber. However, the \\ incising treatment caused a phenomenon in which the incisions connect \\ to each other and develop into surface checks. The wood characteristics, \\ such as species, type, thickness, and initial MC, had more influence on \\ determining the drying defects than the pretreatments. For the commercial \\ use of the drying schedule used in this study, it can be useful to determine \\ the appropriate drying time in the third step according to the species, \\ thickness, and shape.
}

Keywords: Timber drying; Drying defects; Knife-incising; Longitudinal kerfing; High-temperature drying

Contact information: a: Department of Wood Science and Technology, College of Agriculture and Life Science, Jeonbuk National University, 567 Baekje-daero, Deokjin-gu, Jeonju-si, Jeollabuk-do 54896, Republic of Korea; $b$ : Department of Forest Products and Industry, National Institute of Forest Science, Seoul 02455, Republic of Korea; *Corresponding author: willyeom@korea.kr

\section{INTRODUCTION}

Small-diameter logs, such as those obtained from thinning-out trees, provide a poor yield when processed for planks or lumber. However, they can be efficiently used for rafters, park benches, and fences, among other structures. The limitation is the relatively large cross-section of the logs. The moisture movement distance from the core to the evaporation surface is long; and therefore, the deviation in moisture content between the surface layer and the inner layer is high. Therefore, drying the logs to achieve internal moisture content below 19\% is difficult and time-consuming. Moreover, these logs comprise juvenile wood with significant growth stress. Hence, drying defects, such as surface checks and warping, can occur easily. To solve these problems, high-temperature and low-humidity treatment and pretreatment methods, such as longitudinal kerfing and knife-incising, have been explored in several studies (Jung et al. 1997; Yoshida et al. 2000; Lee et al. 2016a, 2017).

High-temperature and low-humidity treatment is effective in preventing surface checks in boxed-heart timber in the initial stage of drying (Yoshida et al. 2000; Hermawan et al. 2012). Pretreatment reduces the time taken to complete a high-temperature drying 
cycle, and it allows a drying set to occur more quickly between the surface layer and the internal layer.

At this time, in the surface layer, a compressive stress corresponding to the tensile stress before the drying set is induced after the drying set, thereby contributing to the reduction of surface checking (Lee et al. 2013).

Longitudinal kerfing has been found to prevent the end checks and splits that commonly occur when drying pith-containing logs (Hsu and Tang 1974). According to the anisotropic shrinkage stress distribution model, the depth of longitudinal kerfing should be one-third of the total thickness of the log (Jung et al. 1997). The longitudinal kerfing does not affect the drying rate of lumber but it is an effective method to prevent surface checks caused by the concentration of stress generated in the surface (Lee et al. 2013, 2014, 2016ac, 2017).

Knife-incising combined with longitudinal kerfing is a common pretreatment used for increasing the penetration of preservatives, but it can also be applied on timbers as a pretreatment for drying. This pretreatment can be applied before drying because it does not affect the permeation of preservatives after drying (Islam et al. 2009; Lee et al. 2017). Moreover, it can prevent surface checks by facilitating the dispersion of stress in the surface layer (Lee et al. 2017). However, because the mechanical properties decrease with increasing density of incising, the incising treatment should only be applied at low density (Suzuki et al. 1996; Park et al. 2008; Lee et al. 2016a).

Despite numerous studies on knife-incising and longitudinal kerfing pretreatments, knowledge of their effects on the occurrence of drying defects remains incomplete. While some studies have reported longitudinal kerfing to reduce the twisting of boxed-heart timber (Lee et al. 2016b,c), other studies reported no such effect (Lee et al. 2013, 2014). Studies have reported prevention of surface checks by knife-incising treatment (Lee et al. 2017). Conversely, the incising can also become connected to each other and thus develop into surface checks (Lee et al. 2016a).

This study was conducted using a commercial dryer to confirm the effects of the incising and kerfing treatment on the occurrence of drying defects in round and square boxed-heart timber with cross-sections measuring $9 \mathrm{~cm}, 12 \mathrm{~cm}$, and $15 \mathrm{~cm}$.

\section{EXPERIMENTAL}

\section{Material Preparation}

Specimens from red pine (Pinus densiflora S. et. Z) and pitch pine (Pinus rigida Mill.) were used in this study (Gangwon-Do, Republic of Korea). Each specimen was processed to form either a square or a round timber with a length of $240 \mathrm{~cm}$ and thickness of one of these three values: $9 \mathrm{~cm}, 12 \mathrm{~cm}$, or $15 \mathrm{~cm}$. Specimens were then divided into four groups according to the applied pretreatment, namely: control (C), knife-incising (I), longitudinal kerfing (K), and a combination of knife-incising and longitudinal kerfing (IK). There were only four incising-treated 15 -cm-thick red pine square specimens as against six specimens of all other categories. This was a result of uncontrolled processing during the pretreatment (Table 1).

The incising treatment was processed with an incising density of approximately 2,400 piece $/ \mathrm{m}^{2}$ using a knife with $2 \mathrm{~mm}$ width and $10 \mathrm{~mm}$ depth (Fig. 1a). Next, longitudinal kerfs were cut on non-incised and incised specimens using a circular saw at one-third depth from the surface along the cross-section on one side of the specimens (Fig. 1b). 
Table 1. Quantity of the Test Specimens According to Species, Type, Size, and Pretreatment Condition

\begin{tabular}{|c|c|c|c|c|c|c|c|}
\hline \multirow{3}{*}{ Size } & \multirow{2}{*}{\multicolumn{3}{|c|}{ Treatment }} & \multicolumn{4}{|c|}{ Number (Pieces) } \\
\hline & & & & \multicolumn{2}{|c|}{ Red Pine } & \multicolumn{2}{|c|}{ Pitch Pine } \\
\hline & & & & Square & Round & Square & Round \\
\hline \multirow{4}{*}{$9 \mathrm{~cm}$} & \multirow{2}{*}{ Non-kerfed } & Control & $\mathrm{C}$ & 6 & 6 & 6 & 6 \\
\hline & & Incising & 1 & 6 & 6 & 6 & 6 \\
\hline & \multirow{2}{*}{ Kerfed } & Control & $\mathrm{K}$ & 6 & 6 & 6 & 6 \\
\hline & & Incising & $\mathrm{KI}$ & 6 & 6 & 6 & 6 \\
\hline \multirow{4}{*}{$12 \mathrm{~cm}$} & \multirow{2}{*}{ Non-kerfed } & Control & $\mathrm{C}$ & 6 & 6 & 6 & 6 \\
\hline & & Incising & 1 & 6 & 6 & 6 & 6 \\
\hline & \multirow{2}{*}{ Kerfed } & Control & $\mathrm{K}$ & 6 & 6 & 6 & 6 \\
\hline & & Incising & $\mathrm{KI}$ & 6 & 6 & 6 & 6 \\
\hline \multirow{4}{*}{$15 \mathrm{~cm}$} & \multirow{2}{*}{ Non-kerfed } & Control & $\mathrm{C}$ & 6 & 6 & 6 & 6 \\
\hline & & Incising & 1 & 4 & 6 & 6 & 6 \\
\hline & \multirow{2}{*}{ Kerfed } & Control & $\mathrm{K}$ & 6 & 6 & 6 & 6 \\
\hline & & Incising & $\mathrm{KI}$ & 6 & 6 & 6 & 6 \\
\hline \multicolumn{4}{|c|}{ Total Quantity } & 70 & 72 & 72 & 72 \\
\hline
\end{tabular}

\section{b. Longitudinal kerfing}

(cross section)

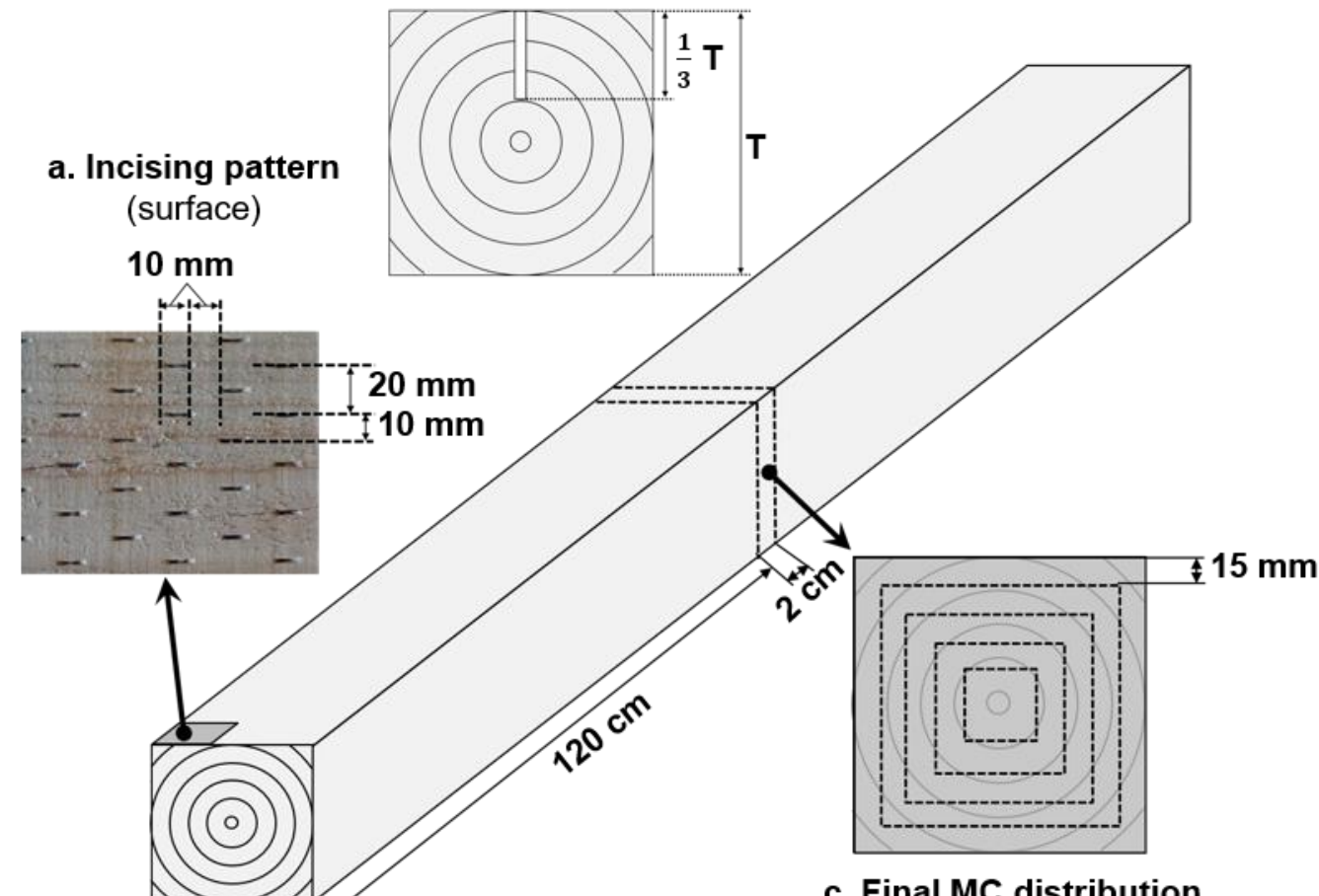

Fig. 1. Processing diagram of the specimens (a: incising pattern, b: longitudinal kerfing, $\mathbf{c}$; final MC distribution) 


\section{Drying Test}

The drying test was performed using a commercial dryer (SKD-90HPT, Shinshiba and Co., Asahikawa, Japan) with a volume capacity of approximately $40 \mathrm{~m}^{3}$. Specimens were stacked in an open pile using wood stickers of dimensions $3 \mathrm{~cm} \times 3 \mathrm{~cm} \times 100 \mathrm{~cm}$. The drying schedule is shown in Table 2 . Two concrete slabs of dimensions $180 \mathrm{~cm} \times 180$ $\mathrm{cm} \times 20 \mathrm{~cm}$, each weighing approximately $1,600 \mathrm{~kg}$, were used for top loading.

Table 2. Drying Schedule

\begin{tabular}{|c|c|c|c|}
\hline Step & $\begin{array}{c}\text { Time } \\
\text { (h) }\end{array}$ & $\begin{array}{c}\text { Dry-bulb } \\
\left({ }^{\circ} \mathbf{C}\right)\end{array}$ & $\begin{array}{c}\text { Wet-bulb } \\
\left({ }^{\circ} \mathbf{C}\right)\end{array}$ \\
\hline $\mathbf{1}$ & 12 & 95 & 95 \\
\hline $\mathbf{2}$ & 36 & 120 & 90 \\
\hline $\mathbf{3}$ & 96 & 90 & 70 \\
\hline $\mathbf{4}$ (Cooling) & 24 & - & - \\
\hline Total Time (h) & $\mathbf{1 6 8}$ & & \\
\hline
\end{tabular}

\section{Moisture Content and Drying Defects}

All specimens were weighed before and after drying. The heaviest specimen according to each condition before drying was selected for shrinkage and moisture content (MC) investigation after drying (Lee et al. 2013, 2014, 2016a-c, 2017). Shrinkage of the four long surfaces and the kerf widening rate were measured at a distance of $120 \mathrm{~cm}$ from the cross-sectional end (Lee et al. 2013, 2014, 2016a-c, 2017). Next, samples, approximately $2 \mathrm{~cm}$ thick, were taken from the same site where previous measurements on shrinkage and kerf widening were recorded. These samples were taken at depths of $1.5 \mathrm{~cm}$ intervals from the surface (Fig. 1-c) (Lee et al. 2016a-c, 2017). The final MC and its distribution were investigated in these samples by the oven-dry method (ISO 3130, 1975). The initial MC was calculated from the final MC of the excised samples and the change in weight of the entire specimens before and after drying (Lee et al. 2016b,c, 2017).

Drying defects were investigated in all specimens after the drying test (Lee $e t$ al. 2013, 2014, 2016a-c, 2017). The length and width of surface checks were measured for all checks of widths greater than $2 \mathrm{~mm}$. The average number and length of the surface checks were determined based on the width of the surface checks. Twist was measured on all four surfaces of the specimens.

$$
\text { Average surface check number and length }=\frac{\sum_{1}^{n} w}{N}
$$

where $\boldsymbol{w}$ is the surface check number and length of according to the surface check width, and $\boldsymbol{N}$ is the number of specimens.

\section{RESULTS AND DISCUSSION}

\section{Final MC and MC Distribution}

The final MC and MC distribution showed variations according to species, size, shape, and pre-treatment conditions (Fig. 2, Tables 3 and 4). The MC after drying was higher in square timber than that in round timber. Although increasing thickness led to an increase in the $\mathrm{MC}$ and a steep moisture gradient after drying, pretreatment tended to decrease the MC after drying. 
Table 3. Initial MC, Final MC, Shrinkage, and Kerf Widening Rate of Red Pine According to Type, Size, and Pretreatment Condition

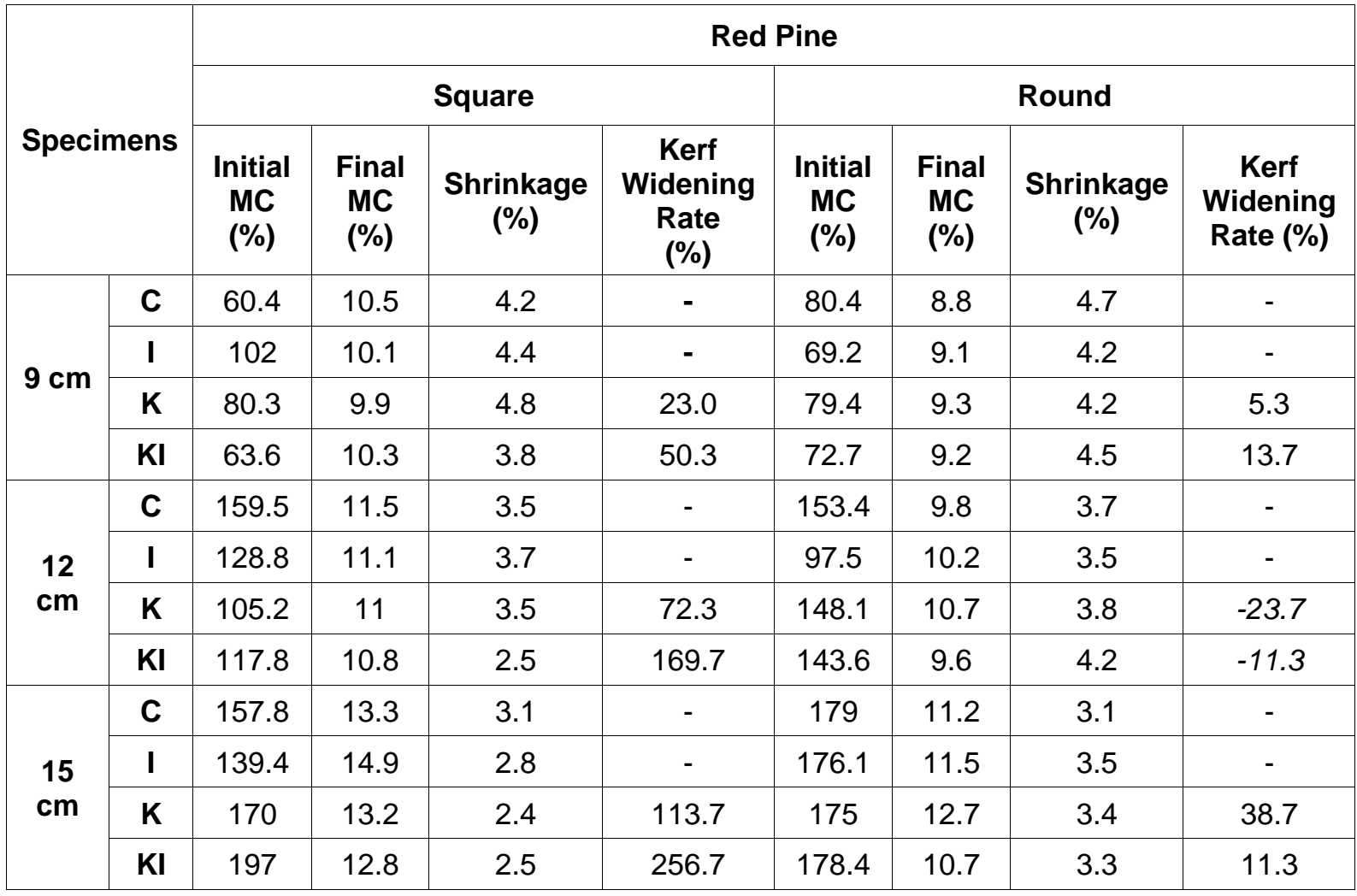

Table 4. Initial MC, Final MC, Shrinkage, and Kerf Widening Rate of Pitch Pine According to Type, Size, and Pretreatment Condition

\begin{tabular}{|c|c|c|c|c|c|c|c|c|c|}
\hline \multirow{3}{*}{\multicolumn{2}{|c|}{ Specimens }} & \multicolumn{8}{|c|}{ Pitch Pine } \\
\hline & & \multicolumn{4}{|c|}{ Square } & \multicolumn{4}{|c|}{ Round } \\
\hline & & $\begin{array}{c}\text { Initial } \\
\text { MC } \\
(\%)\end{array}$ & $\begin{array}{l}\text { Final } \\
\text { MC } \\
(\%)\end{array}$ & $\begin{array}{c}\text { Shrinkage } \\
(\%)\end{array}$ & $\begin{array}{c}\text { Kerf } \\
\text { Widening } \\
\text { Rate (\%) }\end{array}$ & $\begin{array}{c}\text { Initial } \\
\text { MC } \\
(\%)\end{array}$ & $\begin{array}{l}\text { Final } \\
\text { MC } \\
(\%)\end{array}$ & $\begin{array}{c}\text { Shrinkage } \\
(\%)\end{array}$ & $\begin{array}{c}\text { Kerf } \\
\text { Widening } \\
\text { Rate }(\%)\end{array}$ \\
\hline \multirow{4}{*}{$9 \mathrm{~cm}$} & C & 108.5 & 7.9 & 4.0 & - & 71.1 & 8.7 & 3.3 & - \\
\hline & $\mathbf{I}$ & 123.7 & 8.1 & 3.7 & - & 88.3 & 9.1 & 3.2 & - \\
\hline & $\mathrm{K}$ & 96.4 & 7.1 & 2.8 & 2.7 & 86.4 & 8.8 & 3.8 & -27.0 \\
\hline & KI & 98.2 & 8.5 & 4.3 & -0.7 & 75.8 & 8.9 & 4.1 & -62.0 \\
\hline \multirow{4}{*}{$\begin{array}{l}12 \\
\mathrm{~cm}\end{array}$} & C & 131.7 & 13.6 & 2.8 & - & 161.7 & 9.1 & 3.4 & - \\
\hline & I & 171.7 & 11.5 & 4.1 & - & 129.5 & 11.1 & 3.7 & - \\
\hline & $\mathrm{K}$ & 119 & 10.6 & 3.3 & 86.3 & 151.3 & 9 & 3.4 & -100.0 \\
\hline & KI & 118.4 & 10.7 & 3.0 & 249.0 & 113.5 & 9.6 & 4.7 & -100.0 \\
\hline \multirow{4}{*}{$\begin{array}{l}15 \\
\mathrm{~cm}\end{array}$} & C & 162.9 & 18.5 & 1.6 & - & 182.2 & 12.8 & 2.6 & - \\
\hline & I & 124.6 & 23.8 & 0.9 & - & 198.2 & 12.2 & 3.0 & - \\
\hline & $\mathrm{K}$ & 186 & 15.6 & 2.3 & 232.3 & 170.2 & 11.5 & 3.8 & -100.0 \\
\hline & $\mathrm{KI}$ & 185.8 & 15.2 & 2.6 & 125.7 & 229.4 & 12.6 & 2.4 & 47.0 \\
\hline
\end{tabular}



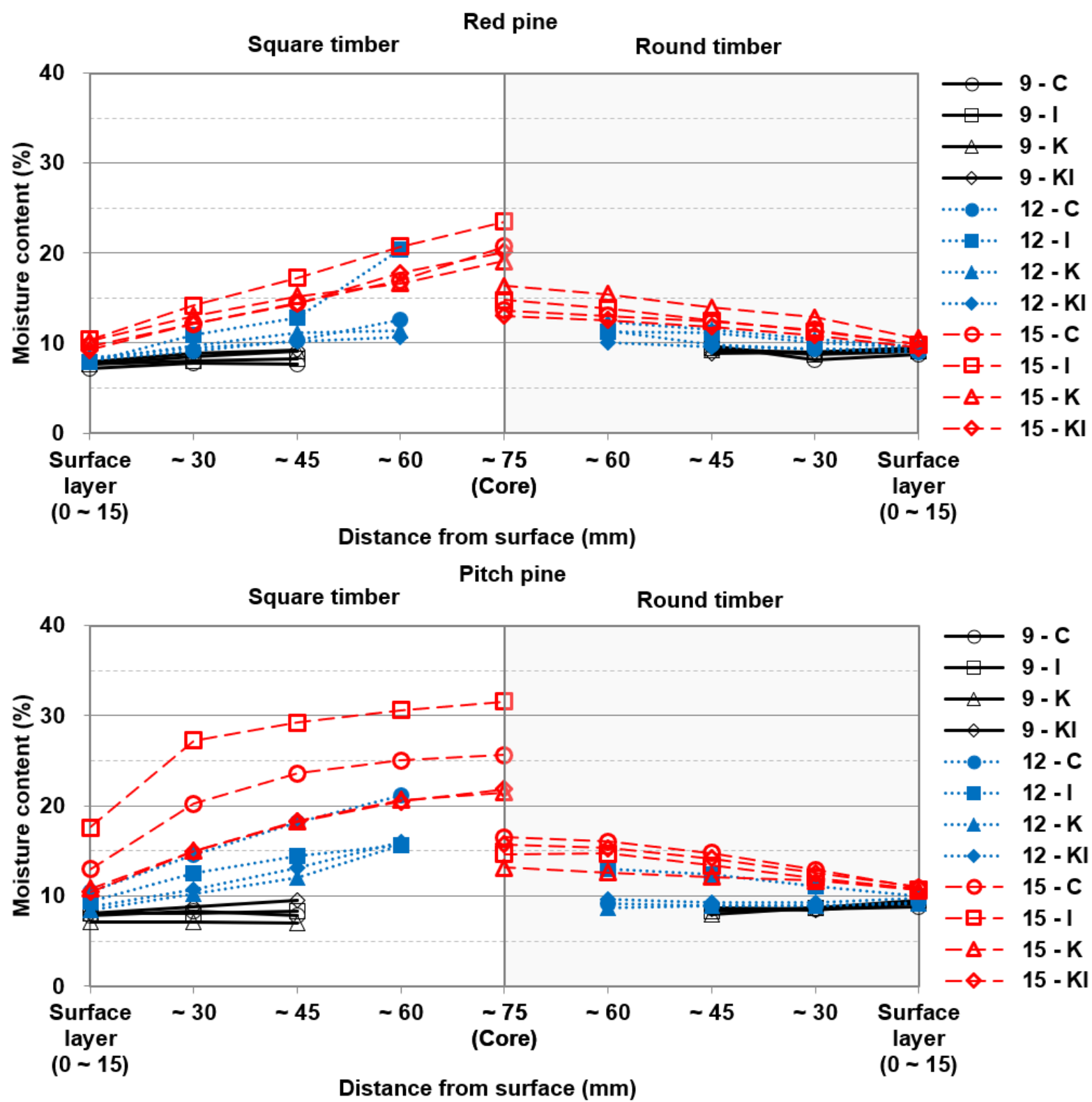

Fig. 2. Moisture content distribution according to the distance from surface layer

Permeability of wood varies among species because this property is influenced by factors such as specific gravity, extractive content, latewood percentage, and wood microstructure (particularly in the types with bordered pits) (Jee and Kim 1996; Hur and Kang 1997). Moreover, the distance from the core to the evaporation surface depends on factors such as shape, thickness, and pretreatment conditions. The incising and kerfing treatment affects the distribution of MC (Lee et al. 2013, 2016a,c). Therefore, because the same drying schedule as in the studies by Lee et al. $(2013,2016 \mathrm{a}, \mathrm{c})$ was used in the present study, the observed differences in the final MC and MC distribution after drying were attributed to the variations in species, shape and thickness of specimens, and pretreatment.

For the commercial drying schedule used in this study, it can be useful to determine the appropriate drying time according to the species, thickness, and shape. It is suggested that the drying time should be controlled in step 3 of Table 2 . 
Generally, the initial MC may affect the final MC and its distribution after drying. Because the drying time was same for all specimens in this study, specimens with a low initial MC should have had a lower final MC than that of specimens with a higher initial MC. However, for the 15-cm-thick square timbers of red pine and pitch pine, although the initial MC was low, the final MC after drying was relatively higher, especially in the incised specimens. In this study, the specimens were exposed to ambient air during preparation before the drying test.

During air drying, pit aspiration reduces the permeability to approximately onetenth to three-tenths of the initial permeability value (Erickson and Crawford 1959). Thus, based on the results, it was speculated that the study on the effect of initial MC on pit aspiration, drying time, and final MC of boxed-heart timber after drying is needed.

\section{Surface Checks}

More surface checks occurred in square timbers than in the round timbers, and this aspect was influenced noticeably by the timber thickness (Tables 5 through 7). As shown in Tables 3 and 4, shrinkage tended to decrease with increasing thickness.

Shrinkage is initiated by a change in MC and leads to the development of drying stresses, such as creep, tension set, and twisting stress (Kubojima et al. 2013). The creep and tension set are greatly affected by drying time and develop differently depending on species, type, thickness, and heart/sapwood ratio (Hwang and Park 2009; Yamashita et al. 2014; Lee et al. 2016c).

For round timbers, the entire surface is composed of tangential section and the distance to be traversed by moisture from the center to the surface for evaporation is shorter than that in the square timbers. Additionally, surface checks can occur when the twisting stress in square timber is suppressed by external forces during drying (Kubojima et al. 2013). Round timber is less affected than square timber by the external forces during drying. Because the moisture gradient between the surface layer and the inner layer increases with increasing thickness and the inner layer suppresses the shrinkage of the surface layer during drying (Lazarescu and Avramidis 2008), the tensile stress formed on the surface layer is not only greater with increasing thickness but also lasts for a longer time. Therefore, the difference in the internal stress behaviors due to the type and thickness of the wood was judged to be the cause of the variation in the occurrence of surface checks.

The incising and kerfing treatments had a significant effect on the occurrence of surface checks, in line with earlier reports (Lee et al. 2013, 2014, 2016a-c, 2017). The kerfing treatment contributed noticeably to the reduction in surface checks in square timber. The kerf widening rate was considered unrelated to the occurrence of surface checks. The results of incising treatment indicated that surface checks occurred differently according to species, type, and thickness of wood.

It was also observed that incising caused a phenomenon in which the incising connects to each other and develop into surface checks. As a result, it was concluded that incising is not a suitable pretreatment for surface checks. Kerfing was judged to be a more appropriate pretreatment for reducing surface checks in some cases.

Nevertheless, the surface check results indicated that pretreatment was not required for round timbers, nor for square timbers of thickness $12 \mathrm{~cm}$ or less. The kerfing treatment noticeably reduced the occurrence of surface checks only in the $15-\mathrm{cm}$-thick red pine and pitch pine square timbers. In general, the incising and kerfing treatments contribute to both the improvement in drying quality and in the development of an optimal drying schedule. 


\section{bioresources.com}

Table 5. Average Length and Number of Surface Checks in Square Timbers According to Surface Checks Width

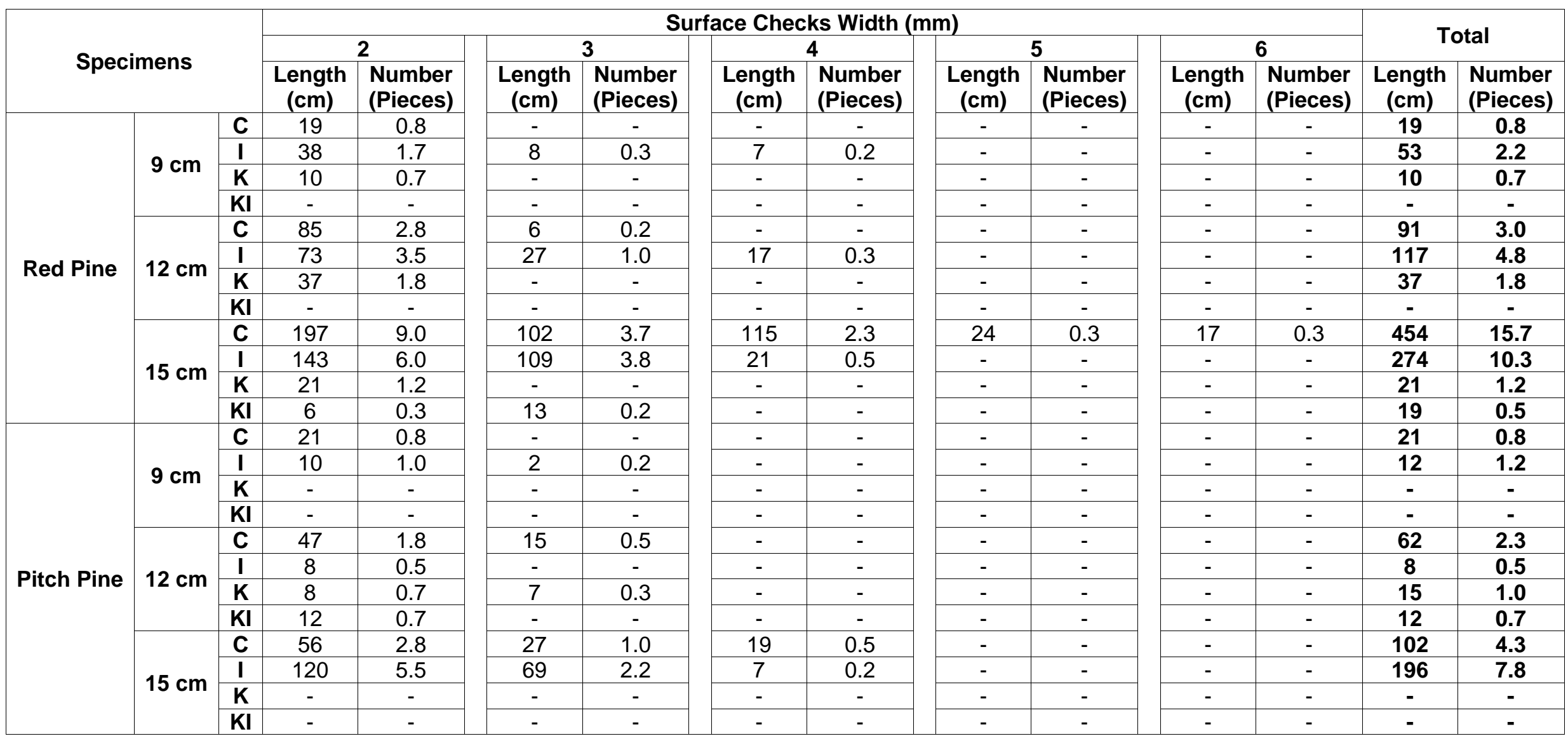


Table 6. Average Length and Number of Surface Checks in Round Timbers According to Surface Checks Width

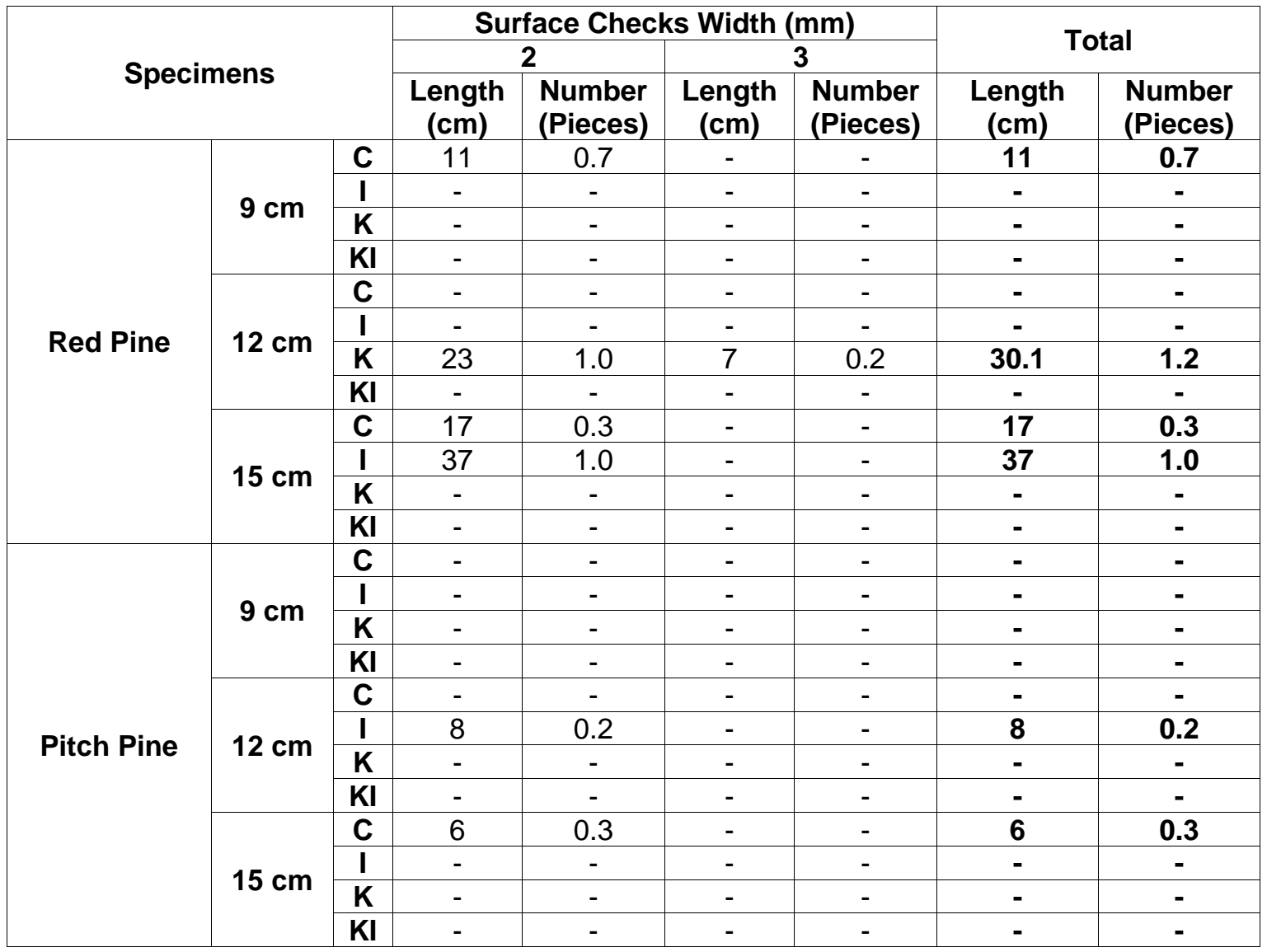

Table 7. Quantity of Specimens Without Surface Checks Over $2 \mathrm{~mm}$ Width

\begin{tabular}{|c|c|c|c|c|c|}
\hline \multirow{2}{*}{\multicolumn{2}{|c|}{ Specimens }} & \multicolumn{4}{|c|}{ Number (Pieces) } \\
\hline & & \multicolumn{2}{|c|}{ Red Pine } & \multicolumn{2}{|c|}{ Pitch Pine } \\
\hline & & Square & Round & Square & Round \\
\hline \multirow{4}{*}{$9 \mathrm{~cm}$} & C & 4 & 5 & 5 & 6 \\
\hline & $\mathbf{I}$ & 3 & 6 & 5 & 6 \\
\hline & $\mathrm{K}$ & 5 & 6 & 6 & 6 \\
\hline & KI & 6 & 6 & 6 & 6 \\
\hline \multirow{4}{*}{$12 \mathrm{~cm}$} & C & 1 & 6 & 4 & 6 \\
\hline & I & 2 & 6 & 5 & 5 \\
\hline & $\mathrm{K}$ & 3 & 5 & 5 & 6 \\
\hline & KI & 6 & 6 & 5 & 6 \\
\hline \multirow{4}{*}{$15 \mathrm{~cm}$} & C & 0 & 4 & 3 & 5 \\
\hline & I & 0 & 4 & 2 & 6 \\
\hline & $\mathrm{K}$ & 5 & 6 & 6 & 6 \\
\hline & KI & 5 & 6 & 6 & 6 \\
\hline \multicolumn{2}{|c|}{ Non-surface Checks } & 40 & 66 & 58 & 70 \\
\hline \multicolumn{2}{|c|}{ Surface Checks } & 30 & 6 & 14 & 2 \\
\hline
\end{tabular}




\section{Twist}

Figure 3 shows that twist, especially in red pine, tended to decrease in the $12-\mathrm{cm}-$ and 15-cm-thick specimens with the application of kerfing treatment. Conversely, twist was increased in the timbers treated by incising. This suggests that the incising and kerfing treatment can affect twist in wood.

Although juvenile wood displays severe shrinkage anisotropy, the twist occurrence of boxed-heart timber after drying is associated with the change in grain angle with respect to distance from the pith (Frühwald 2007). Many studies have reported that grain angle is the most important factor in the occurrence of twist and that kerfing treatment reduced the twisting of boxed-heart timbers from hemlock, radiate pine, and red pine (Frühwald 2006, 2007; Nilsson et al. 2007; Straže et al. 2011; Kubojima et al. 2013; Lee et al. 2016b, 2016c). In contrast, Lee et al. $(2013,2014)$ reported that kerfing had no effect on the twisting of $20-\mathrm{cm}$-thick red pine and Korean pine. In general, it was concluded that the kerfing treatment can contribute to the reduction of twisting, depending on the species and the thickness of the timber.

The incising treatment not only evenly distributes the tensile stress in the surface layer, but also reduces the distance moisture has to traverse from core to surface (Lee et al. 2016a). Tension set occurs at a position farther from the surface than in the absence of the incising treatment. Tension sets can affect warping that occurs with shrinkage because when a tension set occurs in the surface layer and the inner layer, the surface layer suppresses the shrinkage of the inner layer. The incising treatment may make a difference in the degree to which the surface layer suppresses the shrinkage of the inner layer. However, the incising treatment in this study did not show a clear trend of increase or decrease in twist.

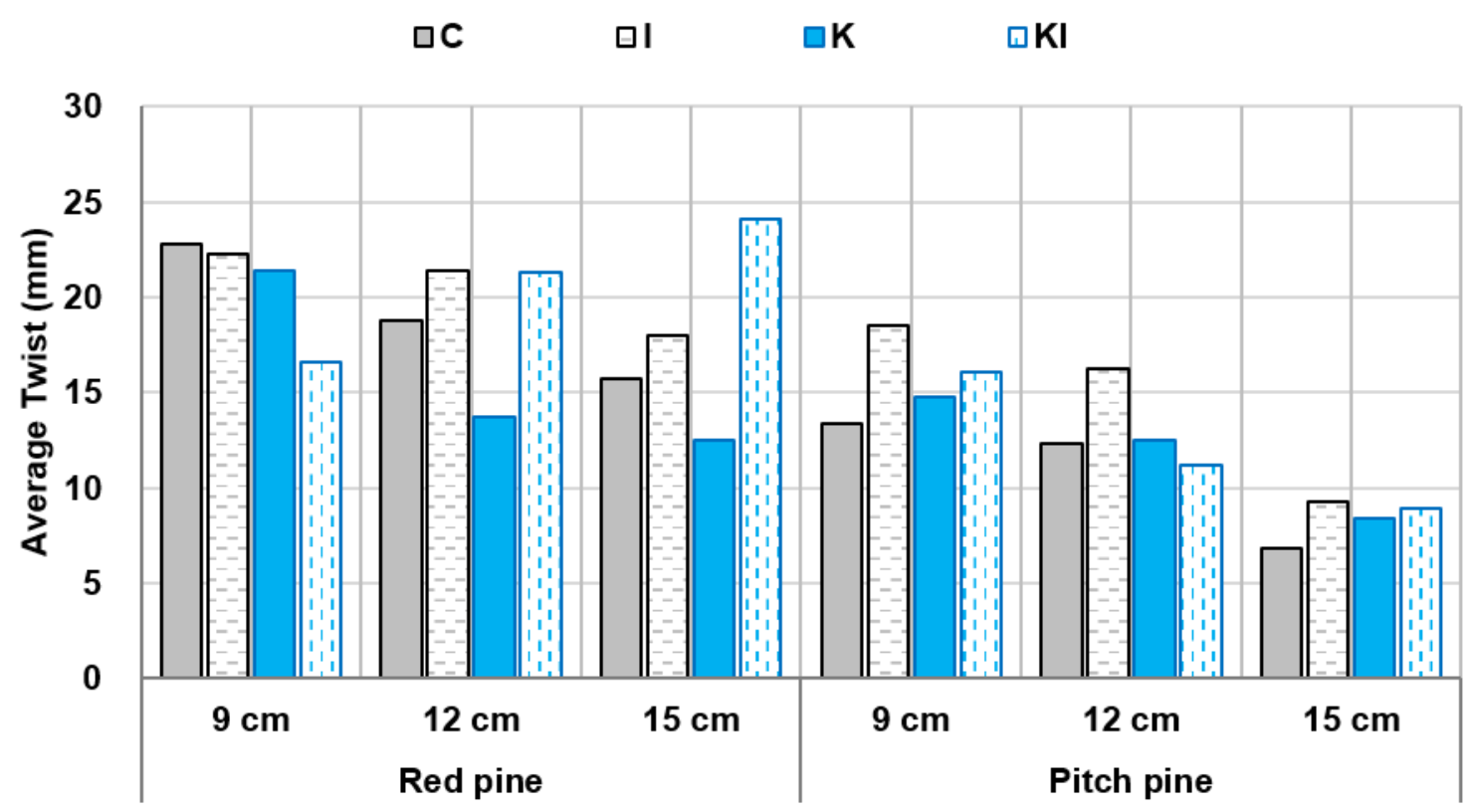

Fig. 3. Average twist of square timber according to species, size, and pretreatment condition 


\section{CONCLUSIONS}

This study evaluated the effects of knife-incising and longitudinal kerfing pretreatments on the softwood timbers with cross-section less than $15 \mathrm{~cm}$. The results could be used for commercial purposes because they were derived from a commercial dryer.

1. Depending on the specific species or thickness of specimens, the kerfing treatment was suitable as a pretreatment for reducing the occurrence of surface defects, and it contributed to the better reduction of twist in red pine than that in pitch pine.

2. The incising treatment affects the internal stress behavior of the wood but is not suitable as a pretreatment because it leads to the interconnections among the incising features leading to the development of surface checks.

3. The wood conditions, such as species, type, thickness, and initial moisture content (MC), were more important than pretreatment for the drying defects.

4. For the commercial use of the drying schedule used in this study, it can be useful to determine the appropriate drying time according to the species, thickness, and shape. Drying time should be controlled in step 3 of the drying schedule shown in Table 2.

5. The incising and kerfing treatments can be used to improve the drying quality and as a tool for deriving an optimal drying schedule.

\section{ACKNOWLEDGMENTS}

This work (No. S2075092) was supported by "Business for Start-up Growth Technology Development" -funded Korea Small and Medium Business Administration in 2012.

\section{REFERENCES CITED}

Erickson, H. D., and Crawford, R. J. (1959). "The effects of several seasoning methods on the permeability of wood to liquids," Proceedings of $55^{\text {th }}$ Annual Meeting of American Wood-Preservers Association, pp. 210-220.

Frühwald, E. (2006). "Improvement of shape stability by high-temperature treatment of Norway spruce effects of drying at $120^{\circ} \mathrm{C}$ with and without restraint on twist," $\mathrm{Holz}$ als Roh-und Werkstoff 64(1), 24-29. DOI: 10.1007/s00107-005-0039-y

Frühwald, E. (2007). "Effects of high drying temperatures and restraint on twist of larch (Larix)," Wood Material Science \& Engineering 2(2), 55-65. DOI: 10.1080/17480270701770598

Hermawan, A., Fujimoto, N., and Sakagami, H. (2012). "Effects of high-temperature and low-humidity pretreatment on the drying properties of sugi boxed-heart timber with black-colored heartwood," Drying Technology 30(7), 780-786. DOI: 10.1080/07373937.2012.663433

Hsu, N., and Tang, R. (1974). "Internal stresses in wood logs due to anisotropic shrinkage," Wood Science 7(1), 43-51. 
Hur, J. Y., and Kang H. Y. (1997). "Measurement of longitudinal liquid permeability using pressure bomb method," Journal of the Korean Wood Science and Technology 25(3), 66-74.

Hwang, K. H., and Park, B. S. (2009). "Effect of cross-sectional dimension on the shrinkage property of Korean red-pine wood," Journal of the Korean Wood Science and Technology 37(3), 231-238.

Islam, M. N., Ando, K., Yamauchi, H., and Hattori, N. (2009). "Effects of species and moisture content on penetration of liquid in laser incised lumber by the passive impregnation method," European Journal of Wood and Wood Products, 67, 129-133. DOI: $10.1007 / \mathrm{s} 00107-008-0292-y$

ISO 3130 (1975). "Wood test methods - Determination of moisture content for physical and mechanical tests," International Organization Standardization, Geneva, Switzerland

Jee, W. K., and Kim, G. H. (1996). "Air permeability of softwoods imported from the Russian far east," Journal of the Korean Wood Science and Technology 24(4), 22-31.

Jung, H. S., Lee, N. H., and Park, J. H. (1997). "The characteristics of vacuum drying heated by hot plates for the thinned logs and pillars of Korean pine," Journal of the Korean Wood Science and Technology 25(4), 51-60.

Kubojima, Y., Kobayashi, I., Yoshida, T., Matsumoto, H., Suzuki, Y., and Tonosaki, M. (2013). "Twisting force during drying of wood," European Journal of Wood and Wood Products 71(6), 689-695. DOI: 10.1007/s00107-013-0732-1

Lazarescu, C., and Avramidis, S. (2008). "Drying related strain development in restrained wood," Drying Technology 26(5), 544-551. DOI: 10.1080/07373930801944697

Lee, C. J., Lee, N. H., Eom, C. D., Shin, I. H., Park, M. J., and Park, J. S. (2013). "Effect of end-coating around pith of heavy timbers of red pine and Korean pine on hightemperature and low-humidity drying characteristics," Journal of the Korean Wood Science and Technology 41(3), 221-233. DOI: 10.5658/WOOD.2013.41.3.221

Lee, C. J., Lee, N. H., Park, M. J., Park, J. S., and Eom, C. D. (2014). "Effect of reserve air-drying of Korean pine heavy timbers on high-temperature and low-humidity drying characteristics," Journal of the Korean Wood Science and Technology 42(1), 49-57. DOI: 10.5658/WOOD.2014.42.1.49

Lee, C. J., Lee, N. H., and Oh, S. W. (2016a). "Effects of the knife-incising and kerfing pretreatment on moisture content and surface check occurrence of Douglas-fir heavy timber," Journal of the Korean Wood Science and Technology 44(3), 302-314. DOI: 10.5658/WOOD.2016.44.3.302

Lee, C. J., Lee, N. H., and Oh, S. W. (2016b). "Effects of the knife-incising and longitudinal kerfing treatment on high-temperature drying characteristics of red pine square timber," Journal of the Korean Wood Science and Technology 44(5), 677-684. DOI: $10.5658 /$ WOOD.2016.44.5.677

Lee, C. J., Lee, N. H., and Oh, S. W. (2016c). "Studies on the high-Temperature drying characteristics of Douglas-fir, hemlock and radiata pine square timber," Journal of the Korean Wood Science and Technology 44(5), 726-735. DOI: 10.5658/WOOD.2016.44.5.726

Lee, C. J., Oh, S. W., Lee, N. H., and Kang, C. W. (2017). "Effect of the knife-incising pretreatment on the surface checks occurrence of red pine heavy timber after drying," European Journal of Wood and Wood Products 75(1), 143-145. DOI:

10.1007/s00107-016-1107-1 
Nilsson, B., Sjödén, T., Nordebo, S., and Säll, H. (2007). “A method for under-bark detection of the wood grain angle radial dependence," Wood Material Science and Engineering 2(3-4), 118-129. DOI: 10.1080/17480270801945330

Park, J. C., Kim, S. W., Ryu, J. Y., and Hong, S. I. (2008). "Strength property of the incised larix (Larix kaempferi Carr.) round posts treated with CCA," Journal of the Korean Wood Science and Technology 36(3), 85-92.

Straže, A., Kliger, R., Johansson, M., and Gorišek, Ž. (2011). "The influence of material properties on the amount of twist of spruce wood during kiln drying," European Journal of Wood and Wood Products 69, 239-246. DOI: 10.1007/s00107-010-0422-1

Suzuki, K., Teduka, Y., Ando, K., Hattori, N., Kitayawa, S., Kato, H., Nagao, H., Tanaka, T. (1996). "Laser incising of wood, the effect of incising density on bending strength of sugi square lumber (in Japanese)," Proceedings of the $46^{\text {th }}$ Annual Meeting of the Japanese Wood Research Society. p.130

Yamashita, K., Hirakawa, Y., Saito, S., Nakatani, H., Ikeda, M., and Ohta, M. (2014). "Effect of cross-sectional dimensions on bow and surface checking of sugi (Cryptomeria japonica) boxed-heart square timber dried by conventional kiln drying," Journal of Wood Science 60(1), 1-11. DOI: 10.1007/s10086-013-1380-0

Yoshida, T., Hashizume, T., and Fujimoto, N. (2000). "High-temperature drying characteristics on boxed-heart square timber of karamatsu [Larix leptolepis] and sugi [Cryptomeria japonica]: Influences of high temperature conditions with low humidity on drying properties," Wood Industry 55(8), 357-362.

Article submitted: August 11, 2021; Peer review completed: October 4, 2021; Revised version received and accepted: October 14, 2021; Published: October 20, 2021.

DOI: 10.15376/biores.16.4.8184-8196 